\title{
Biodecolorization of Azo Dye Acid Blue 113 by Soil Bacterium Klebsiella variicola RMLP1
}

\author{
Pradeep Kumar Singh', Pankaj Singh ${ }^{2}$, Rajat Pratap Singh ${ }^{3}$ and Ram Lakhan Singh ${ }^{1,4^{*}}$ \\ 'Department of Biochemistry, Dr. Rammanohar Lohia Avadh University, Ayodhya - 224001, Uttar Pradesh, \\ India; drrlsingh@rediffmail.com \\ 2Department of Biotechnology, Dr. Rammanohar Lohia Avadh University, Ayodhya - 224001, Uttar Pradesh, India \\ ${ }^{3}$ Department of Biotechnology, Guru Ghasidas University, Koni, Bilaspur - 495009, Chhattisgarh, India \\ ${ }^{4}$ Vice-Chancellor, Nilamber-Pitamber University, Medininagar, Palamu - 822101, Jharkhand, India
}

\begin{abstract}
The present study was aimed to isolate a new bacterial strain for the degradation/decolorization of azo dye Acid Blue 113 (AB 113). The physico-chemical method is inadequate for degradation of azo dyes; therefore, an environmental friendly and competent method such as use of the biological organism was studied for decolorization of AB 113. Bushnell and Hass (BHM) medium containing AB 113 dye were used to perform the decolorization study. 16S rRNA gene sequencing approach was used for identification of bacterial isolate as a Klebsiella variicola. The optimum process parameters for the decolorization of $\mathrm{AB} 113$ were found at $\mathrm{pH} 8,35^{\circ} \mathrm{C}$ temperature and $100 \mathrm{mg} / \mathrm{L}$ dye concentration during $72 \mathrm{~h}$ incubation. Glucose and ammonium sulphate was the carbon and nitrogen source suited well for the decolorization of dye. The results proved that the Klebsiella variicola, offer huge ability in treating textile wastewater containing the color AB 113.
\end{abstract}

Keywords: Acid Blue 113, Azo Dye, Decolorization, Klebsiella Variicola, 16S rDNA

\section{Introduction}

Synthetic dyes are xenobiotic, aromatic compounds which provide permanent color to various materials. These dyes offer broad range of color shades and consume minimum energy during their appliance in the textile, food, paper, paint, varnish, cosmetics and pharmaceutical industries ${ }^{1}$. On the basis of structure of chromophore, 20 different types of dye groups are available ${ }^{2}$. The textile processing industries produces huge quantity of azo dye $\mathrm{e}^{3}$. It was estimated that globally $7 \times 10^{5}$ metric tons of textile color is generated each year and $70 \%$ of this vast amount is contributed by azo dyes ${ }^{4}$. About $10-15 \%$ of the azo dyes used in dyeing process is unbound and are likely to be discharged into water bodies. 5 . Azo dyes are cyclic organic preparations comprise one or more azo bond $(-\mathrm{N}=\mathrm{N}-)$. These bonds are accountable for recalcitrant nature of dyes and give resistant capacity towards its natural degradation. Discharge of these dyes into environment decreases light dispersion into water which minimize the photosynthetic process of aquatic species $^{6}$. These dyes are also mutagenic ${ }^{7}$ and carcinogenic to human and other aquatic animals ${ }^{8}$. Number of physicochemical techniques for example, flocculation, ion exchange, membrane filtration, coagulation, photo-oxidation, electrolysis and ozonation are used for textile wastewater treatment but, they have some limitations such as generation of large quantities of toxic chemical sludge and high operational and maintenance $\operatorname{cost}^{9}$. As physico-chemical techniques are associated with some limitation, there is a need to develop some more efficient and cost-effective methods for the removal of these dyes from wastewater. The biological methods include bacterial decolorization, fungal decolorization, phycoremediation, phytoremediation and enzymatic methods ${ }^{10}$. Thus, biological microorganisms such as bacteria, fungi, algae, and plants are successfully used in the decolorization and degradation of these dyes. These microbial based decolorization and degradation methods have some decisive advantages such as low operating cost, efficient and production of less sludge and eco-friendly nature ${ }^{11}$. The major benefits of biological methods are low preparation techniques and easy maintenance of microbes ${ }^{12}$. The decolorization process by fungi and algae attributed to adsorption rather than degradation which result in retention of dye in the environment. Bacterial degradation of dyes primarily begins under anaerobic conditions by an enzyme mediated step ${ }^{13}$. The ensuing degradation products for

${ }^{*}$ Author for correspondence 
example toxic aromatic amines are further cleaved by multistep route either aerobically or anaerobically ${ }^{14}$.

This study aims to isolate and identify the potential of bacterial strain for decolorization of Acid Blue 113 dye and optimization of various nutritional and physical conditions.

\section{Materials and Methodology}

\subsection{Dyes and Chemicals}

The dye Acid Blue 113 (AB 113) and other azo dyes used in this study were purchased from Sigma-Aldrich Chemicals. All the other chemicals and media components were of highest purity and of an analytical grade.

\subsection{Medium Used for Culture Studies}

Bushnell and Haas medium (BHM) having $\mathrm{MgSO}_{4} 0.2 \mathrm{~g} / \mathrm{L}$, $\mathrm{K}_{2} \mathrm{HPO}_{4} 1.0 \mathrm{~g} / \mathrm{L}, \mathrm{CaCl}_{2} 0.02 \mathrm{~g} / \mathrm{L}, \mathrm{FeCl}_{3} 0.05 \mathrm{~g} / \mathrm{L}, \mathrm{NH}_{4} \mathrm{NO}_{3}$ $1.0 \mathrm{~g} / \mathrm{L})$, yeast extract $(0.05 \% \mathrm{w} / \mathrm{v})$ and glucose $(0.1 \% \mathrm{w} / \mathrm{v})$ was employed in this study.

\subsection{Isolation and Screening of Decolorizing Bacteria}

Soil samples were collected from the different sites of Tanda, Ambedkar Nagar, Uttar Pradesh (India). These soil samples along with BHM amended with dye AB 113 (100 mg/L) were employed to isolate and screen the dye decolorizing strain. Soil suspension $(10 \% \mathrm{w} / \mathrm{v})$ was prepared and $10 \mathrm{ml}$ aliquots were transferred into an Erlenmeyer flask having $100 \mathrm{ml}$ of dye containing media. After several times repeated transfers into fresh dye containing media, dye decolorization was achieved. The decolorized samples were serially diluted, and dilutions were subsequently plated on BHM agar plates containing 100 $\mathrm{mg} / \mathrm{L} \mathrm{AB} 113$ dye. The isolates showing visible decolorization zones with distinctive morphology were streaked on $100 \mathrm{mg} / \mathrm{L}$ $\mathrm{AB} 113$ dye containing BHM agar plates. The bacterial isolate that showed the highest decolorizing ability of $\mathrm{AB} 113$ dye was designated as BT-9.

\subsection{Bacterial Identification by 16s rRNA Gene Amplification and Sequencing with BLAST Analysis}

A fresh single colony of bacterial strain BT-9 was inoculated in $50 \mathrm{ml}$ of Luria Bertani (LB) broth and maintained at $37^{\circ} \mathrm{C}$ temperature in a shaker incubator for $24 \mathrm{hrs}$. After centrifugation at $8000 \mathrm{rpm}$ of broth culture, the genomic DNA was extracted by Qiagen genomic DNA purification kit by using cell pellet. The purified DNA was used for the amplification of 16S rRNA gene. A $50 \mu$ reaction of prepared Master Mix (Promega) and 50 ng genomic DNA of isolate BT-9 was added along with 10 picomols of each primer (27f-1492R) and mixed properly ${ }^{15}$. The Polymerase chain reaction was performed in a thermal cycler (BioRad My-cycler) and after the completion of the PCR, amplicons were stored at $-20^{\circ} \mathrm{C}$ for further qualitative assessment by Agarose gel electrophoresis. Amplification product $(2 \mu \mathrm{l})$ mixed with $6 \mathrm{X}$ gel loading dye was loaded on $1.2 \%$ agarose gel and electrophoresis was run for $4 \mathrm{hrs}$ at 60 V. $1 \mathrm{~kb}$ DNA marker ladder (Promega) was used for the assessment of amplicon size and agarose gel was visualized in gel-documentation system (BioRad) and the image was saved.

16S rRNA gene PCR product was purified (Qiagen) and processed for DNA sequencing. DNA sequencing was performed by Sanger dideoxy sequencing (BigDye Terminator Sequencing Kit V3.0) on ABI 3130XL Genetic Analyzer (Applied Biosystems USA). DNA sequence was checked for quality and a performed nucleotide BLAST (BLASTn, NCBI, USA) analysis. Neighbor-Joining method used to conduct evolutionary analysis by using the MEGA 6 software ${ }^{16}$.

\subsection{Effects of Various Process Parameters on AB 113 Decolorization}

Effects of various process parameters such as incubation condition (shaking and static), $\mathrm{pH}(4.0,5.0,6.0,7.0,8.0$, and 9.0), temperature $\left(20-40^{\circ} \mathrm{C}\right.$ interval), carbon source (glucose, fructose, sucrose, maltose, starch and lactose), nitrogen source (peptone, ammonium sulphate, ammonium nitrate, yeast extract, and ammonium chloride), dye AB 113 concentration $(100,200,300,400,500$ and $600 \mathrm{mg} / \mathrm{L})$ on decolorization of $\mathrm{AB}$ 113 were investigated. All the experiments were carried out in triplicate in $15 \mathrm{ml}$ screw capped tubes under static condition.

\subsection{Decolorization of Various Textile Dyes by Klebsiella variicola RMLP1}

Decolorization efficiency of Klebsiella variicola RMLP1 was tested with structurally different azo dyes. In this experiment five different azo dyes, namely Direct Blue 71, Reactive Red 120, Acid Orange, Congo Red and Metanil Yellow with concentration $(100 \mathrm{mg} / \mathrm{L})$ were used under the optimized process parameters.

\subsection{Decolorization Manner of Klebsiella variicola RMLP1 Strain on Acid Blue 113}

To study the decolorization manner of Klebsiella variicola RMLP1 strain on Acid Blue 113, heatkilled and livebacterial cells were used. A bacterial cell suspension was autoclaved at $121^{\circ} \mathrm{C}$ for 30 minutes. The culture medium containing autoclaved bacterial suspension was used to test the decolorization limit. 
Culture medium having live bacterial suspension was used as a control. Both heat killed and live bacterial cells containing medium were used to perform decolorization activity under the static condition for $72 \mathrm{~h}$ of incubation. After incubation, samples were centrifuged at $10,000 \mathrm{rpm}$ for $10 \mathrm{~min}$ at $4^{\circ} \mathrm{C}$. To spot any alteration of dye structure following decolorization, UV-Visible spectrophotometer (Labtronics) was used to scan decolorized sample supernatant from $200 \mathrm{~nm}$ to $800 \mathrm{~nm}$.

\subsection{Measurement of Decolorization Efficiency}

To assess the decolorization efficiency, samples were collected at every $12 \mathrm{~h}$ intervals. The samples were centrifuged at 10,000 rpm for $10 \mathrm{~min}$ at $4^{\circ} \mathrm{C}$ and were studied by quantification of culture supernatant absorbance at $566 \mathrm{~nm}$. The decolorization potential was mentioned as percentage of decolorization ${ }^{17}$.

Decolorization $(\%)=\frac{\text { Initial absorbance }- \text { Final absorbance }}{\text { Initial absorbance }} \mathrm{X} 100$

\subsection{Statistical Study}

All experiment was performed in triplicate. Microsoft Excel was used to calculate standard deviation (SD) and results presented as mean $\pm \mathrm{SD}$ value.

\section{Results}

\subsection{Isolation and Identification by Sequencing 16S rRNA Gene}

Dye decolorizing bacterial strain was isolated from soil sample collected from wastewater contaminated sites of Tanda, Uttar Pradesh, India. BT-9 bacterial strain which showed highest potential to decolorize $\mathrm{AB} 113$ dye was isolated for further study by using BHM medium.

$16 \mathrm{~S}$ rRNA gene sequence approach was used for identification of bacterial strain BT-9. Bacterial strain BT-9 was identified (with 99\% sequence similarity) as Klebsiella variicola after the nucleotide BLAST (BLASTn, NCBI, USA) analysis. The DNA sequence was submitted to the GenBank database (NCBI, USA) and accession number (KY794214) was received. Phylogenetic analysis was performed by MEGA 6 software ${ }^{16}$. 16S rRNA gene sequences from 10 closely related Klebsiella were downloaded from NCBI database. All 10 DNA sequences along with strain RMLP1 were used for phylogenetic analysis and DNA sequence from Rickettsia was used as out group. Dendrogram showed that strain RMLP1 is closely related to the Klebsiella variicola (Figure 1).

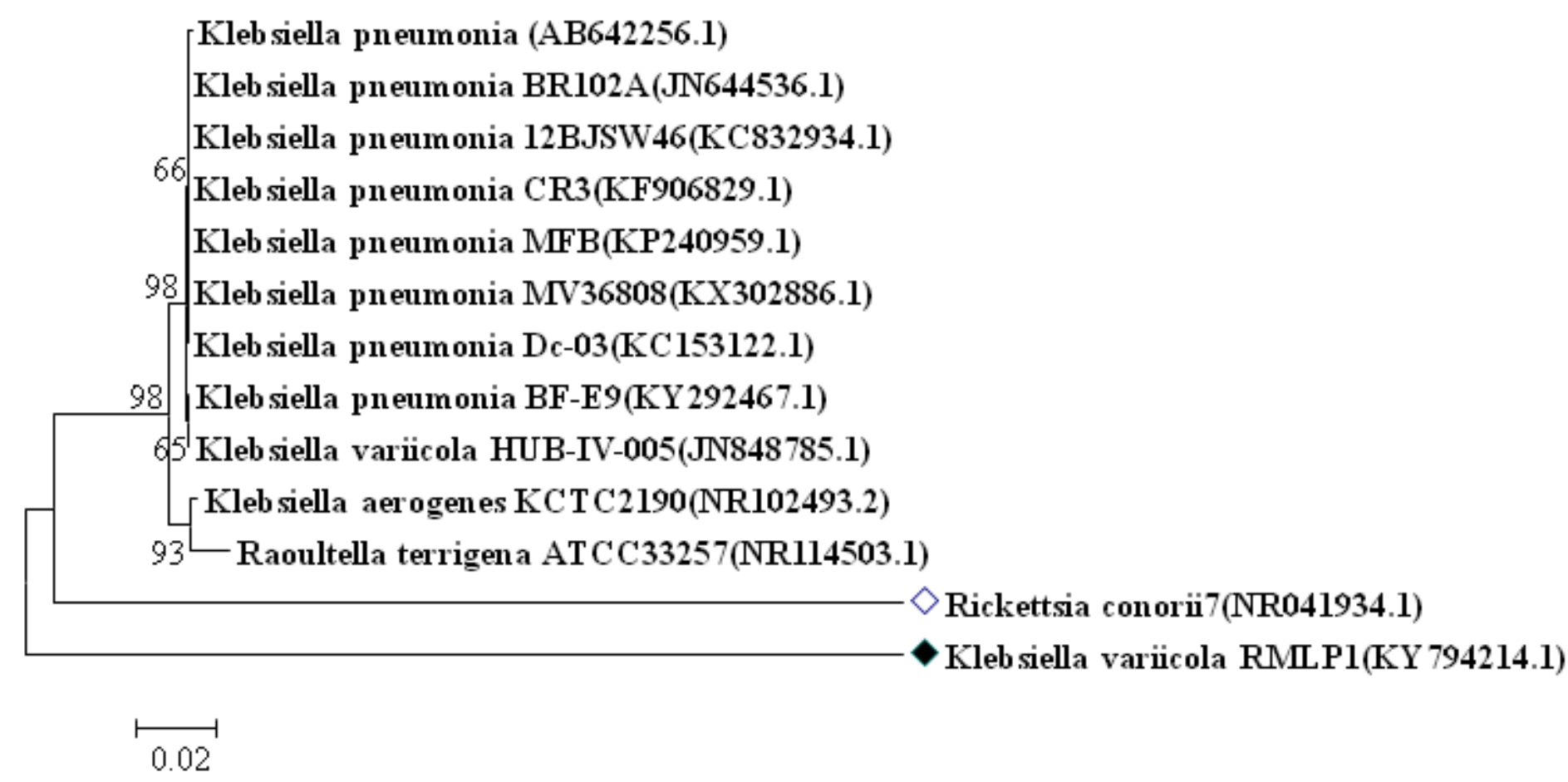

Figure 1. Dendrogram of the Klebsiella variicola RMLP1 strain. 


\subsection{Effect of Incubation Condition}

Physiological characteristics of the cells such as growth and development are highly influenced by presence and absence of oxygen. It was believed that oxygen inhibits the dye decolorization process as it possesses high redox potential. The Klebsiella variicola RMLP1 strain showed $80.66 \%$ color removal of Acid Blue 113 in static condition while only 31.03\% color removal observed in shaking environment (Figure 2).

\subsection{Effect of $\mathrm{pH}$ and Temperature}

For effective growth and metabolic activity of bacteria, $\mathrm{pH}$ and temperature are two very important physical factors. The optimum $\mathrm{pH}$ and temperature is a demand of bacterial cell which contribute in successful decolorization of dyes. In natural environment $\mathrm{pH}$ occurs in a range of 5 to 9 . Since $\mathrm{pH}$ is considered as a rate limiting factor as it responsible for transport of dye across the bacterial cell membrane for dye decolorization. The maximum decolorization (86.48\%) of $\mathrm{AB}$ 113 dye by Klebsiella variicola RMLP1 strain was found at $\mathrm{pH}$ 8 (Figure 3). A further deviation in either side of $\mathrm{pH} 8$ leads to reduction of decolorization percentage.

Klebsiella variicola RMLP1 strain showed increased decolorization of $\mathrm{AB} 113$ dye as temperature increases from $20-35^{\circ} \mathrm{C}$ (Figure 4). Beyond $35^{\circ} \mathrm{C}$ temperature decolorization efficiency of the strain RMLP1 was considerably decreases. Thus, optimal temperature was found to be $35^{\circ} \mathrm{C}$ with $90.53 \%$ color removal of AB 113 dye by Klebsiella variicola RMLP1 strain.

\subsection{Effect of Carbon and Nitrogen Source}

Carbon and nitrogen source are necessary for the successful color removal by bacteria. These sources are involved in enhancement of metabolic functioning and bacterial growth and concurrently facilitate the decolorization process by reduction of azo bond. The bacterial strain Klebsiella variicola RMLP1 showed maximum decolorization of $\mathrm{AB} 113$ by using these sources as a co-substrate. Maximum decolorization (91.01\%) was achieved with carbon source glucose. The sucrose, fructose, maltose, lactose and starch were seem to be less suitable source of carbon with $74.13 \%, 48.92 \%, 29.46 \%$, 49.98\% and 22.59\% decolorization of AB 113 dye, respectively (Figure 5).

The extent of color removal by Klebsiella variicola RMLP1 strain was tested with various nitrogen sources such as peptone, yeast extract, ammonium chloride and ammonium sulphate. The highest rate of decolorization (93.43\%) was achieved with the ammonium sulphate, whereas $73.43 \%, 91.19 \%, 50.49 \%$ and $46.75 \%$ decolorization of $\mathrm{AB} 113$ dye respectively was observed, with the ammonium nitrate, yeast extract, peptone and ammonium chloride nitrogen sources (Figure 6).

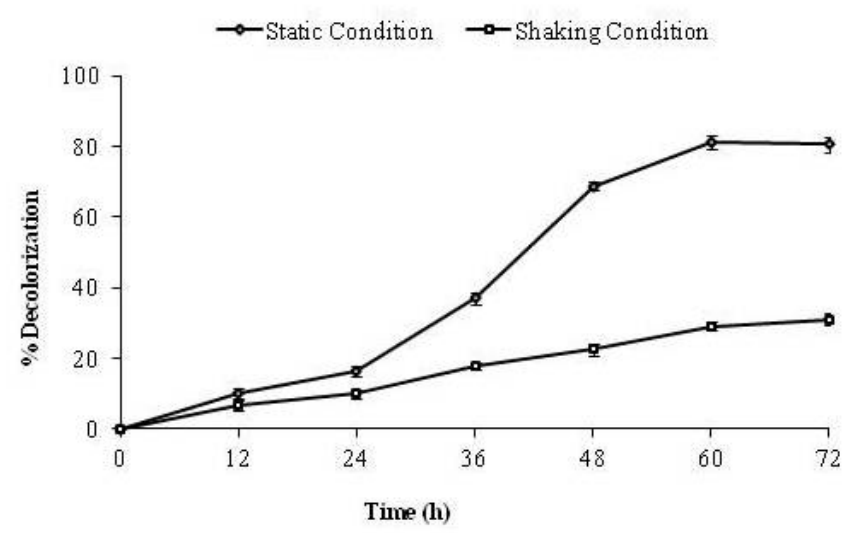

Figure 2. Effect of incubation conditions.

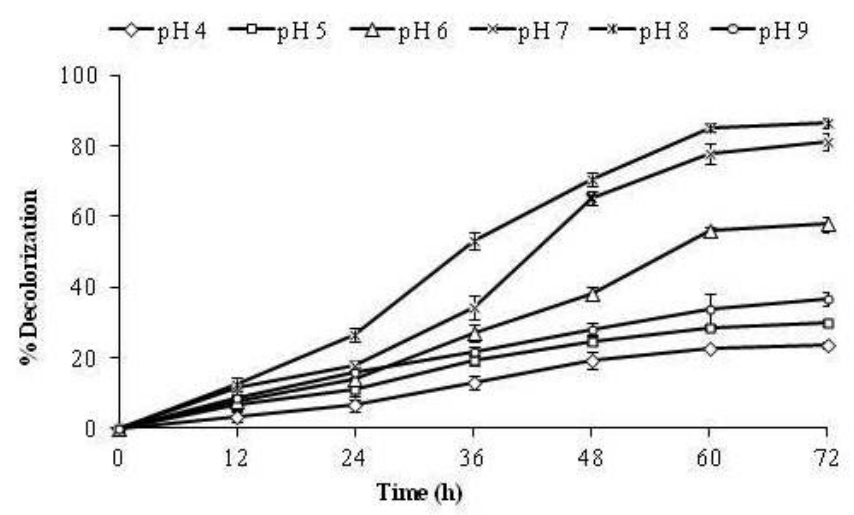

Figure 3. Effect of $\mathrm{pH}$.

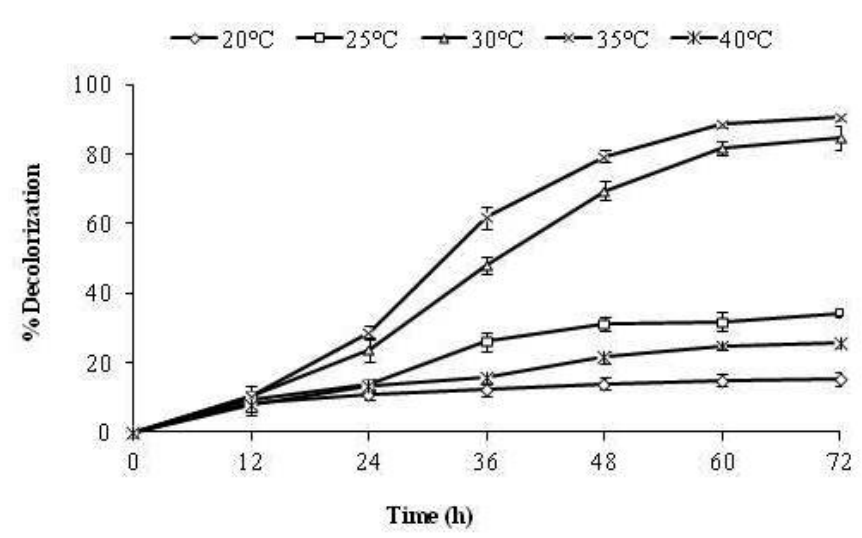

Figure 4. Effect of Temperature.

\subsection{Effect of $A B 113$ Dye Concentration}

The rate of dye decolorization largely depends on dye concentration present in a medium. The Klebsiella variicola RMLP1 strain showed low color removal of AB 113 dye at higher concentration of dye. The highest decolorization up to $92.75 \%$ of $A B 113$ was achieved by RMLP1 strain at $100 \mathrm{mg} / \mathrm{L}$ concentration of dye. Further increase from 200 to $600 \mathrm{mg} / \mathrm{L}$ of dye concentration leads to reduction in decolorization rates (Figure 7). 


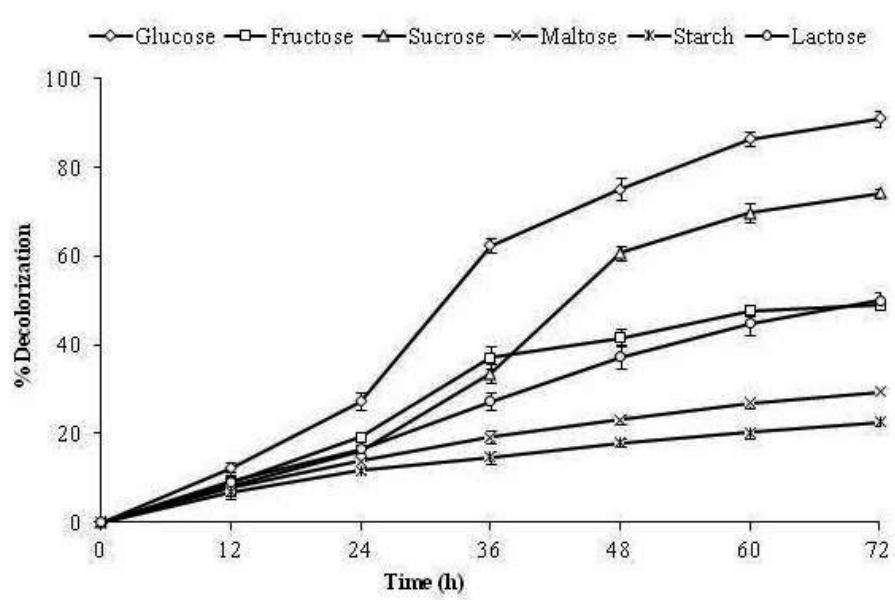

Figure 5. Effect of various carbon sources.

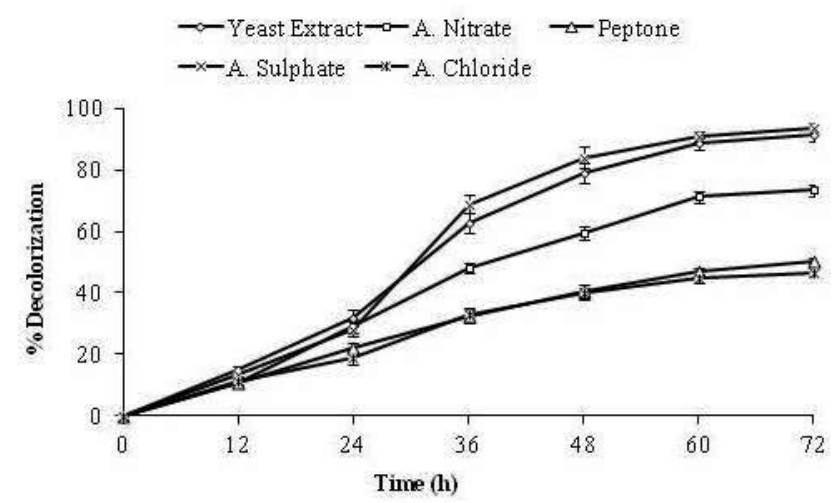

Figure 6. Effect of various nitrogen sources.

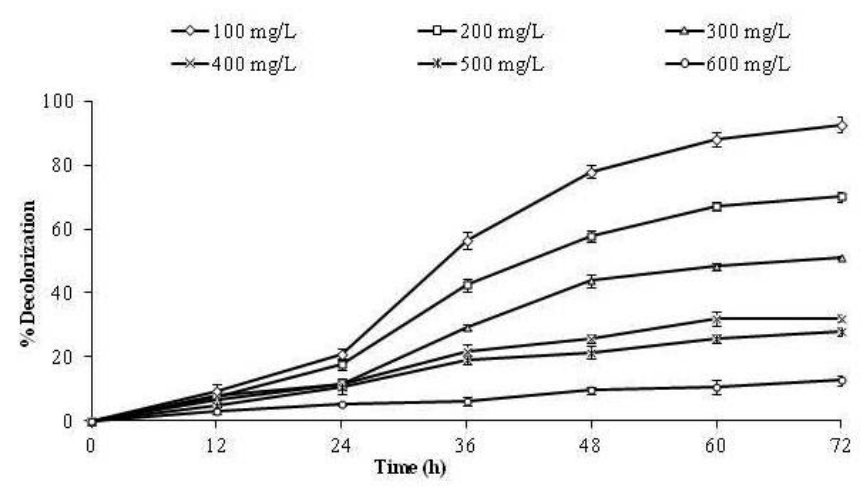

Figure 7. Effect of $\mathrm{AB} 113$ dye concentration.

\subsection{Decolorization of Various Textile Dyes by Klebsiella variicola RMLP1}

All test dyes were decolorized up to different extent by Klebsiella variicola RMLP1 at its optimized physico-chemical and nutritional conditions for decolorization of $\mathrm{AB} 113$ dye. The highest decolorization of $88.68 \%$ was achieved for Direct Blue 71. Other four dyes including Reactive Red 120, Acid Orange,
Congo Red and Metanil Yellow were decolorized up to $79.54 \%$, $62.01 \%, 51.06 \%$ and $29.25 \%$, respectively. The difference in the color removal extent of various dyes attributed to structural complexity of test dyes ${ }^{18}$. The decolorization efficiency of Klebsiella variicola RMLP1 against all the azo dyes tested in this study showed that Klebsiella variicola RMLP1 might be utilized in decolorization of recalcitrant dye containing wastewater.

\subsection{Decolorization Manner of Klebsiella variicola RMLP1 Strain Against Acid Blue 113}

Decolorization of azo dyes may be due to adsorption ${ }^{19}$ or degradation ${ }^{20}$. During adsorption bacterial cells only adsorbed dyes onto its surface, whereas degradation process involved in generating new compounds via reduction of azo bond by bacterial enzymes. If the decolorization is due to degradation either the major absorbance peak of visible region will entirely disappear or a new peak wills emerge ${ }^{21}$. The medium having autoclaved bacterial cells (heat killed) achieved only $16.92 \%$ decolorization after $72 \mathrm{~h}$ incubation with blue colored cell pellets. This low decolorization extent might be due to the adsorption phenomenon showed by heat killed bacterial cells. In the control experiment, $88.41 \%$ decolorization of AB 113 was observed after $72 \mathrm{~h}$ of incubation (Figure 8). The spectral scan from 200 to $800 \mathrm{~nm}$ of supernatants after treatment proved that absorbance peak maxima at $566 \mathrm{~nm}$ in visible region completely disappeared in control culture (Figure 9). The change of absorption pattern in UV and visible region proved that the $\mathrm{AB} 113$ dye molecular structure was altered after decolorization. The azo bond was the primary chromophore of AB113 which was responsible for blue color of dye. The change in visible spectra indicated that the primary chromophore was destroyed due to the cleavage of azo bond during the decolorization reaction. These findings suggested that the decolorization of $\mathrm{AB} 113$ dye by Kleibsella variicola

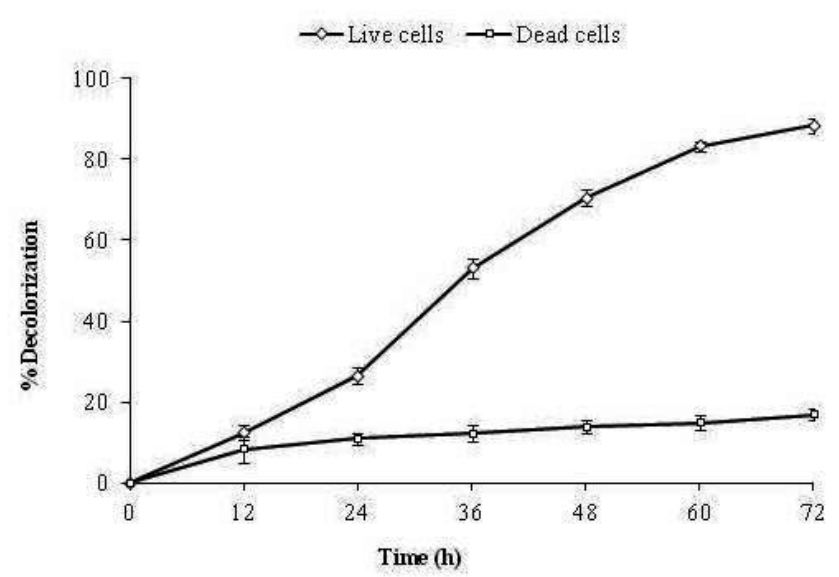

Figure 8. Decolorization of AB 113 by live cells and dead cells (heat-killed) of Kleibsella variicola RMLP1strain. 


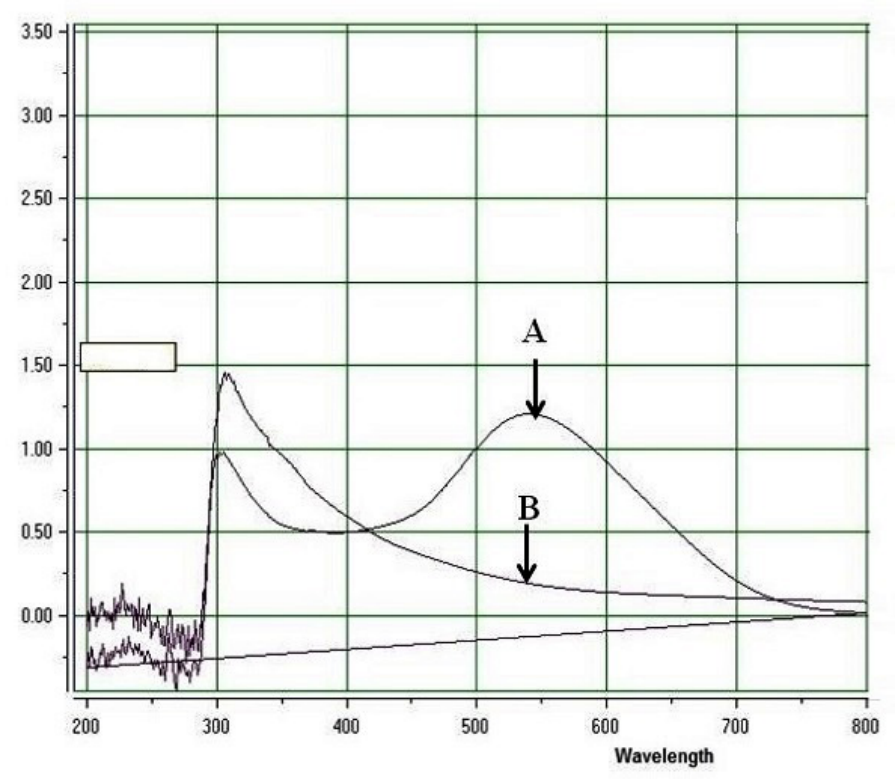

Figure 9. Variation in the UV-visible spectra of AB 113 before and after decolorization by Kleibsella variicola RMLP1 strain (A, 0 h: B, 72 h).

RMLP1 was due to the biodegradation rather than adsorption. Many researchers concluded that the biodegradation instead of adsorption is the mode for dye decolorization by bacteria which supports our study ${ }^{22,23}$.

\section{Discussion}

The bacterial strain Klebsiella variicola RMLP1 efficiently decolorized the $\mathrm{AB} 113$ dye under static condition. Ghodake et al. ${ }^{24}$ have found similar result for decolorization of Amaranth dye by using bacterium Acinetobacter calcoaceticus under static condition. Isik and Sponza ${ }^{25}$ observed $100 \%$ color removal of dye Congo Red with Pseudomonas sp. in static condition as compared to non-static condition, where $45 \%$ decolorization of Direct Black 38 was reported. It was also reported that Citrobacter sp. CK3 successful removal of dye Reactive Red 180 by more than $96 \%$ under static conditions whereas in shaking condition only $13 \%$ color removal was achieved ${ }^{26}$. In addition, Singh et al. ${ }^{27}$ also studied the potential of Staphylococcus hominis RMLRT03 strain for decolorization of dye Acid Orange under static and shaking condition and found that $85.52 \%$ and $32.47 \%$ color removal respectively. Higher concentration of oxygen under shaking condition inhibits the reductive enzyme accountable for breakdown of azo linkage ${ }^{28}$.

The optimal $\mathrm{pH}$ for decolorization of $\mathrm{AB} 113$ by $K$. variicola RMLP1 strain was found at $\mathrm{pH} 8$. A similar trend of dye decolorization efficiency (89.06\%) by Pseudomonas sp. was also reported at same $\mathrm{pH}^{29}$. Likewise, Das et al. ${ }^{30}$ achieved more than 95\% decolorization of Remazol Navy Blue by Bacillus pumilus HKG212 at pH 8. Similarly, 96\% decolorization of Direct Orange 16 was achieved under static condition by Micrococcus luteus strain SSN2 at $\mathrm{pH} 8^{31}$.

The optimal temperature for decolorization of dye $\mathrm{AB} 113$ by RMLP1 strain was found to be $35^{\circ} \mathrm{C}$ temperature. Similar to our result, Arulazhagan ${ }^{32}$ found that bacterial culture Bacillus subtilis showed $60 \%$ decolorization of Reactive Red M8B at $35^{\circ} \mathrm{C}$. Likewise, Bacillus halodurans MTCC 865 degraded up to $90 \%$ of Acid Black 24 at $37^{\circ} \mathrm{C}$ in static condition ${ }^{33}$. Furthermore, Tripathi and Srivastava ${ }^{34}$ demonstrated that $37^{\circ} \mathrm{C}$ was the most favorable temperature for Orange 10 dye removal with $P$. putida MTCC 102.

Generally, the rate of decolorization of azo dyes was enhanced up to the most favorable temperature by several bacterial sp., after that slight change in temperature leads to reduction of decolorization activity. This decrease in decolorization extent at higher temperature was due to the denaturation of azoreductase enzyme.

Glucose was found as the best carbon source for AB 113 dye decolorization by RMLP1 strain. Similar to our result, Carolin et al. ${ }^{35}$ also noticed nearly 95\% decolorization of Methyl Orange in the presence of glucose using Micrococcus yunnaenensis strain. Wang et al. ${ }^{26}$ demonstrated that Citrobacter CK3 sp., was efficiently remove dye Reactive Red 180 when added glucose in culture medium. It was believed that glucose is preferential carbon source, supports the dye decolorization, and also promotes bacterial growth and development which leads to increased dye decolorization ${ }^{36}$.

In our study ammonium sulphate is found best source of nitrogen for decolorization of AB 113 dye. Similar to our finding, Garg et al. ${ }^{37}$ reported ammonium sulphate as good source of nitrogen for bacterium P. putida SKG-1 to achieve maximum decolorization of dye Acid Orange 7. Equally, Carolin et al..$^{35}$ found effective decolorization of Methyl Orange dye by M. yunnaenensis in presence of yeast extract and peptone mediated nitrogen supplement. The culture medium supplemented with organic/inorganic nitrogen source involved in production of NADH, which facilitates the decolorization of azo dyes by bacterial system via donating the electrons ${ }^{38}$.

The strain RMLP1 showed highest decolorizing activity at dye concentration of $100 \mathrm{mg} / \mathrm{L}$ while above this concentration of dye the rate of decolorization was gradually reduced. The decrease in decolorization extent was attributed to toxicity of dye to bacteria by inhibition of metabolic activity. Ghodake et al. ${ }^{24}$ also reported that the dye concentration $100 \mathrm{mg} / \mathrm{L}$ of Amaranth was removed up to $71 \%$ in $72 \mathrm{hrs}$ by Acinetobacter calcoaceticus but beyond this decolorization activity was not effective. Moreover, Carolin et al. ${ }^{35}$ reported the highest decolorization rate of Methyl Orange by M. yunnaenensis strain at $100 \mathrm{mg} / \mathrm{L}$ and further increase in dye concentration leads to decrease in decolorization rate. 


\section{Conclusion}

In this study, a dye decolorizing bacterial strain, Klebsiella variicola RMLP1 was isolated from soil contaminated with textile effluent. The biodecolorization activity of Klebsiella variicola RMLP1 was mediated through degradation means but not by adsorption. Biodegradation of $\mathrm{AB} 113$ by Klebsiella variicola RMLP1 strain was not earlier described in any other studies. Klebsiella variicola RMLP1 has immense potential for bioremediation of number of azo dyes frequently used in various industries as it possessed potent decolorizing activity.

\section{Acknowledgement}

Authors are very thankful to Dr. Alok Srivastava, Principal Scientist, National Bureau of Agriculturally Important Microorganisms, Mau, Uttar Pradesh, India, for providing 16S rRNA gene sequencing and BLAST analysis to identify the bacterial isolate.

\section{References}

1. Singh PK, Singh RL. Bio-removal of Azo Dyes: A Review. Int J Appl Sci Biotechnol. 2017; 5(2):108-126. https://doi.org/10.3126/ ijasbt.v5i2.16881

2. Benkhaya S, Mrabet S, El Harfi A. Classifications, properties, recent synthesis and applications of azo dyes. Heliyon. 2020; 6(1): e03271. doi.org/10.1016/j.heliyon.2020.e03271.

3. Cui D, Cui M, Liang B, Liu W, Tang Z, Wang A. Mutual effect between electrochemically active bacteria (EAB) and azo dye in bio-electrochemical system (BES). Chemosphere. 2020; 239: 124787. doi: 10.1016/j.chemospere.2019.124787.

4. Sarvajith, Reddy GKK, Nancharaiah YV. Textile dye biodecolorization and ammonium removal over nitrite in aerobic granular sludge sequencing batch reactors. J Hazard Mater. 2017; 342: 536-543. https://doi.org/10.1016/j.jhazmat.2017.08.064

5. Asad S, Amoozegar MA, Pourbabaee AA, Sarbolouki MN, Dastgheib SMM. Decolorization of textile azo dyes by newly isolated halophilic and halotolerant bacteria. Bioresour Technol. 2007; 98: 2082-2088. https://doi.org/10.1016/j. biortech.2006.08.020

6. Singh RL, Singh PK, Singh RP. Recent advances in decolorization and degradation of dyes in textile effluent by biological approaches. Baca Raton New York: CRC Press; 2020. https://doi. org/10.1201/9780429244322

7. Chung KT, Cerniglia CE. Mutagenicity of azo dyes: structure activity relationships. Mutat. Res. 1992; 277: 201-220. https:// doi.org/10.1016/0165-1110(92)90044-A

8. Acuner E, Dilek FB. Treatment of Tectilon Yellow $2 \mathrm{G}$ by Chlorella vulgaris. Process Biochem. 2004; 39: 623-631. https://doi. org/10.1016/S0032-9592(03)00138-9

9. Ayed L, Chaieb K, Cheref A, Bakhrouf A. Biodegradation and decolorization of Triphenylmethane dyes by Staphylococcus epi- dermidis. Desalin. 2010; 260: 137-146. https://doi.org/10.1016/j. desal.2010.04.052

10. Tochhawng L, Mishra VK, Passari AK, Singh BP. Endophytic Fungi: role in dye decolorization. In: Advances in endophytic fungal research, Singh B. (ed), Fungal biology. Springer, Cham. 2019; pp1-15. https://doi.org/10.1007/978-3-030-03589-1_1

11. Singh RL, Singh PK, Singh RP. Enzymatic decolorization and degradation of azo dyes-a review. Int Biodeter Biodegr. 2015; 104: 21-31. https://doi.org/10.1016/j.ibiod.2015.04.027

12. Guo G, Li X, Tian F, Liu T, Yang F, Ding K, Liu C, Chen J, Wang C. Azo dye decolorization by a halotolerant consortium under microaerophilic conditions. Chemosphere. 2020; 244: 125510. doi:10.1016/j.chemosphere.2019.125510.

13. Carvalho MC, Pereira C, Gonçalves IC, Pinheiro HM, Santos AR, Lopes A, Ferra MI. Assessment of the biodegradability of a mono-sulfonated azo dye and aromatic amines. Int Biodeter Biodgr. 2008; 64: 676-681.

14. Barragan BE, Costa C, Marquez MC. Biodegradation of azo dyes by bacteria inoculated on solid media. Dyes Pigments. 2007; 75 : 73-81. https://doi.org/10.1016/j.dyepig.2006.05.014

15. Singh RN, Kaushik R, Arora DK, Saxena AK. Prevalence of opportunist pathogens in thermal springs of devotion. J Appl Sci Environ Sanit. 2013; 8: 195-203.

16. Tamura K, Stecher G, Peterson D, Filipski A, Kumar S. MEGA6: Molecular Evolutionary Genetics analysis. Version 6.0. Mol Biol Evol. 2013; 30: 2725-2729. https://doi.org/10.1093/molbev/ mst197

17. Zimmermann T, Kulla HG, Leisinger T. Properties of purified Orange II azoreductase, the enzyme initiating azo dye degradation by Pseudomonas KF46. Eur J Biochem. 1982; 129: 197-203. https://doi.org/10.1111/j.1432-1033.1982.tb07040.x

18. Kalyani DC, Telke AA, Dhanve RS, Jadhav JP. Eco-friendly Biodegradation and detoxification of Reactive Red 2 textile dye by newly isolated Pseudomonas sp. SUK1. J Hazard Mater. 2008; 163: 735-742. https://doi.org/10.1016/j.jhazmat.2008.07.020

19. Aravindhan R, Rao JR, Nair BU. Removal of basic yellow dye from aqueous solution by sorption on green alga Caulerpa scalpelliformis. J Hazard Mater. 2007; 142: 68-76. https://doi.org/10.1016/j. jhazmat.2006.07.058

20. Kumar K, Devi SS, Krishnamurthi K, Dutta D, Chakrabarti T. Decolorization and detoxification of Direct Blue- 15 by a bacterial consortium. Bioresour Technol. 2007; 98: 3168-3171. https://doi. org/10.1016/j.biortech.2006.10.037

21. Yu ZS, Wen XH. 2005. Screening and identification of yeasts for decolorizing synthetic dyes in industrial wastewater. Int Biodeter Biodegr. 2005; 56: 109-114. https://doi.org/10.1016/j. ibiod.2005.05.006

22. Asad S, Amoozegar MA, Pourbabaee AA, Sarbolouki MN, Dastgheib SMM. Decolorization of textile azo dyes by newly isolated halophilic and halotolerant bacteria. Bioresour Technol. 2007; 98: 2082-2088. https://doi.org/10.1016/j. biortech.2006.08.020

23. Fan L, Zhu SN, Liu DQ, Ni JR. Decolorization of 1-amino-4-bromoanthraquinone-2-sulfonic acid by a newly isolated strain of 
Sphingomonas herbicidovorans. Int Biodeter Biodegr. 2009; 63: 88-92. https://doi.org/10.1016/j.ibiod.2008.07.004

24. Ghodake G, Jadhav U, Tamboli D, Kagalkar A, Govindwar S. Decolorization of textile dyes and degradation of mono azo dye Amaranth by Acinetobacter calcoaceticus NCIM 2890. Indian J Microbiol. 2011; 51: 501-508. https://doi.org/10.1007/s12088011-0131-4

25. Isik M, Sponza DT. Effect of oxygen on decolorization of azo dyes by Escherichia coli and Pseudomonas sp. and fate of aromatic amines. Process Biochem. 2003; 38: 1183-1192. https://doi. org/10.1016/S0032-9592(02)00282-0

26. Wang H, Su JQ, Zheng XW, Tian Y, Xiong XJ, Zheng TL. Bacterial decolorization and degradation of the reactive dye Reactive Red 180 by Citrobacter sp. CK3. Int Biodeter Biodegr. 2009; 63: 395399. https://doi.org/10.1016/j.ibiod.2008.11.006

27. Singh RP, Singh PK, Singh RL. Bacterial decolorization of textile azo dye Acid Orange by Staphylococcus hominis RMLRT03. Toxicol. Int. 2014; 21:160-166. https://doi.org/10.4103/09716580.139797

28. Stolz A. Basic and applied aspects in the microbial degradation of azo dyes. Appl Microbiol Biotechnol. 2001; 56:69-80. https://doi. org/10.1007/s002530100686

29. Ponraj M, Gokila K, Zambare V. Bacterial decolorization of textile dye Orange 3R. Int J Adv Biotechnol Res. 2011; 2:168-177.

30. Das A, Mishra S, Verma VK. Enhanced biodecolorization of textile dye Remazol Navy Blue using an isolated bacterial strain Bacillus pumilus HKG212 under improved culture conditions. J Biochem Technol. 2015; 6:962-969.

31. Singh S, Chatterji S, Nandini PT, Prasad ASA, Rao KVB. Biodegradation of azo dye Direct Orange 16 by Micrococcus luteus strain SSN2. Int J Environ Sci Tech. 2015; 12: 2161-2168. https://doi.org/10.1007/s13762-014-0588-x

32. Arulazhagan P. A study on microbial decolorization of Reactive Red M8B by Bacillus subtilis isolated from dye contaminated soil samples. Int J Curr Res Biol Med. 2016; 1:1-13.

33. Prasad ASA, Rao KVB. Aerobic biodegradation of azo dye Acid Black 24 by Bacillus halodurans. J Environ Biol. 2014; 35: 549554.

34. Tripathi A, Srivastava SK. Eco-friendly treatment of azo dyes: Biodecolorization using bacterial strains. Int J Biosci Biochem Bioinform. 2011; 1:37-40. https://doi.org/10.7763/IJBBB.2011. V1.7

35. Carolin CF, Kumar PS, Joshiba GJ. Sustainable approach to decolorize Methyl Orange dye from aqueous solution using novel bacterial strain and its metabolites characterization. Clean Technol Envir. 2020; doi.org/10.1007/s10098-020-01934-8.

36. Banat IM, Nigam P, Singh D, Marchant R. Microbial decolorization of textile dye containing effluents: A review. Bioresour Technol. 1996; 58(3): 217-227. https://doi.org/10.1016/S09608524(96)00113-7

37. Garg SK, Tripathi M, Singh, SK, Tewari JK. Biodecolorization of textile dye effluent by Pseudomonas putida SKG-1 (MTCC 10510) under the conditions optimized for monoazo dye Orange II color removal in simulated minimal salt medium. Int Biodeter Biodegr. 2012; 74:24-35. https://doi.org/10.1016/j.ibiod.2012.07.007

38. Saratale RG, Saratale GD, Kalayani DC, Chang JS, Govindwar SP. Enhanced decolorization and biodegradation of textile azo dye Scarlet R by using developed microbial consortiumGR. Bioresour Technol. 2009; 100: 2493-2500. https://doi. org/10.1016/j.biortech.2008.12.013 